\title{
Distinct role of clathrin-mediated endocytosis in the functional uptake of cholera toxin ${ }^{\star}$
}

\author{
Davy Vanden Broeck ${ }^{凶}$, Albert R. Lagrou and Marc J. S. De Wolf \\ UA-Laboratory of Human Biochemistry, University of Antwerp, Antwerp, Belgium
}

Received: 23 August, 2007; revised: 20 November, 2007; accepted: 03 December, 2007 available on-line: 10 December, 2007

\begin{abstract}
The involvement of the clathrin-mediated endocytic internalization route in the uptake of cholera toxin (CT) was investigated using different cell lines, including the human intestinal Caco-2 and T84 cell lines, green monkey Vero cells, SH-SY5Y neuroblastoma cells and Madin-Darby canine kidney cells. Suppression of the clathrin-mediated endocytic pathway by classical biochemical procedures, like intracellular acidification and potassium depletion, inhibited cholera toxin uptake by up to about $50 \%$ as well as its ability to raise intracellular levels of cAMP. Also prior exposure of these cell types to the cationic amphiphilic drug chlorpromazine reduced the functional uptake of cholera toxin, even to a greater extent. These effects were dose- and cell typedependent, suggesting an involvement of clathrin-mediated endocytosis in the functional uptake of cholera toxin. For a more straightforward approach to study the role of the clathrin-mediated uptake in the internalization of cholera toxin, a Caco- ${ }^{\text {eps- }}$ cell line was exploited. These Caco$2^{\text {eps- }}$ cells constitutively suppress the expression of epsin, an essential accessory protein of clathrin-mediated endocytosis, thereby selectively blocking this internalization route. CT uptake was found to be reduced by over $60 \%$ in Caco- $2^{\text {eps- }}$ paralleled by a diminished ability of CT to raise the level of cAMP. The data presented suggest that the clathrin-mediated uptake route fulfils an important role in the functional internalization of cholera toxin in several cell types.
\end{abstract}

Keywords: Cholera toxin, clathrin-mediated endocytosis, siRNA, internalization, chlorpromazine

\section{INTRODUCTION}

Cholera toxin $(\mathrm{CT})$, the enterotoxin secreted by the Vibrio cholerae bacteria, classical as well as El Tor biotypes, is the major virulence factor causing acute diarrhoeal disease in humans (de Haan \& Hirst, 2004; WHO, 2006). CT belongs to the superfamily of $\mathrm{AB}$ toxins. The toxin is an oligomeric protein composed of a heterodimeric A-subunit (CT-A, $\left.M_{\mathrm{r}} 27400\right)$ and a homopentameric B-subunit (CT-B,
$M_{\mathrm{r}}$ 58000). CT-B is responsible for binding to the cell surface receptor, monosialoganglioside $\mathrm{GM}_{1}$ (Van Heyningen et al., 1971). CT-A consists of two distinct polypeptide chains $\left(\mathrm{CT}-\mathrm{A}_{1}, M_{\mathrm{r}} 22000\right.$ and CT- $\mathrm{A}_{2}, M_{\mathrm{r}}$ 5400 ) linked by a single disulfide bridge. CT- $\mathrm{A}_{1}$ is a catalytic polypeptide, displaying mono ADP-ribosyl transferase activity. Following ADP-ribosylation of the $G_{s \alpha}$ subunit of the stimulatory GTP-binding regulatory protein $\left(\mathrm{G}_{\mathrm{s}}\right)$, the basolaterally located adenylate cyclase becomes constitutively activated.

\footnotetext{
^This paper is dedicated to Professor Tadeusz Chojnacki from the Institute of Biochemistry and Biophysics, Polish Academy of Sciences in Warsaw on the occasion of the 50th anniversary of his scientific activity and 75th birthday.

$\triangle$ Corresponding author: Davy Vanden Broeck, UA-Laboratory of Human Biochemistry, University of Antwerp, Groenenborgerlaan 171, B2020 Antwerp, Belgium; phone: (0032) 32653329 ; fax: (0032) 3265 3326; e-mail: davy.vandenbroeck@ ua.ac.be

Abbreviations: BCECF-AM, 2',7'-bis(2-carboxyethyl)-5(6)-carboxyfluorescein acetoxymethyl ester; BFA, brefeldin A; CAD, chloramphiphilic drug; $\mathrm{CHC}$, clathrin heavy chain; $\mathrm{CPZ}$, chlorpromazine; CT-A, $-\mathrm{A}_{1}, \mathrm{~A}_{2}$ and -B, A subunit, $\mathrm{A}_{1}$ peptide, $A_{2}$ peptide, and $B$ subunit of cholera toxin; $C T$, cholera toxin; DIG, detergent insoluble glycolipid rich microdomain; FBS, foetal bovine serum; $\mathrm{GM}_{1}$, monosialo-tetrahexosyl-ganglioside; HAc, acetic acid; IBMX, 3-isobutyl-1-methylxanthine; MDCK, Madin-Darby canine kidney cell; M $\beta C D$, methyl- $\beta$-cyclodextrin; NEM, N-ethylmaleimide; PBS, phosphate-buffered saline; TfR, transferrin receptor.
} 
The resulting increase in the intracellular cAMP level causes net salt and water secretion manifested by severe secretory diarrhoea (Vanden Broeck \& De Wolf, 2007).

Several pathways mediating the functional internalization of CT have been proposed. Initially, internalization via non-coated invaginations (Tran et al., 1987) was favoured, gradually changing into an uptake via caveolae-like, detergent-insoluble glycolipid rich microdomains (DIG's) or so-called lipid rafts (Fra et al., 1994; Harder \& Simons, 1997; Orlandi \& Fishman, 1998; Wolf et al., 2002; Fishman \& Orlandi, 2003) supported by the observation that lipid rafts and caveolae are enriched in $\mathrm{GM}_{1}$, by studies visualizing $\mathrm{CT}$ in caveolae and by experiments with drugs perturbing the cholesterol balance of the plasma membrane. On the other hand, several other lines of evidence (e.g., the time course of the intoxication process (De Wolf, 2000), CT response in cells lacking caveolae (Orlandi \& Fishman, 1998), identification of CT in clathrin-coated vesicles (Parton, 1996), genetic approaches (Damke et al., 1994; Torgersen et al., 2001) and the effect of amphiphilic drugs (Shogomori \& Futerman, 2001)) rather point to a role for clathrin-dependent endocytosis in the internalization of CT. Recently, even alternative internalization mechanisms have been proposed such as an entry route regulated by the small GTPase ARF6, which has been demonstrated to interact directly with CT-A (Jobling \& Holmes, 2000; Massol et al., 2004). In addition, simultaneous blocking of all three described internalization routes had no effect on the ability of CT to raise intracellular levels of cAMP, thereby suggesting an involvement of other unidentified endocytic pathways (Massol et al., 2004).

In the present study experimental evidence is presented in favour of an involvement of the clathrin-mediated endocytic machinery in the functional internalization of CT. To this end a number of more classical biochemical strategies including (i) cytosolic acidification, (ii) $\mathrm{K}^{+}$depletion and, (iii) preincubation in the presence of the cationic amphiphilic drug chlorpromazine, all known to specifically interfere with clathrin-mediated endocytosis, have been used. To provide more direct evidence the recently developed and powerful technique of RNA interference (RNAi) was applied targeting the mRNA encoding epsin, an accessory protein of coated pit formation, generating a Caco-2 $2^{\text {eps- }}$ cell line with a highly reduced epsin expression and accordingly a severely impaired clathrinmediated uptake (Vanden Broeck \& De Wolf, 2006).

\section{MATERIALS AND METHODS}

Materials. Highly purified CT was obtained from List Biological Laboratories (Campbell, CA,
USA). HEPES, BSA, methyl- $\beta$-cyclodextrin, chlorpromazine, IBMX, iodixanol were from Sigma (St. Louis, $\mathrm{MO}$, USA). $\mathrm{Na}^{125}$ I was obtained from MP Biochemicals \& Reagents. ${ }^{125}$ I-transferrin (diferric) and protease inhibitor cocktail were from Roche Diagnostics (Mannheim, Germany). Clathrin heavy chain (CHC) antibodies were purchased from Santa Cruz Biotechnology Inc. (Santa Cruz, CA, USA). BCECF-AM was obtained from Invitrogen-Molecular Probes.

Radiolabelling. CT was radiolabelled following the Iodo-gen method as described by Fraker and Speck (1978).

Cell culture. Except for the green monkey Vero cell line, obtained from Flow Laboratories, all other cell lines were purchased from ATCC. T84 human intestinal epithelial cells were grown in a $1: 1(\mathrm{v} / \mathrm{v})$ mixture of Ham's F12 and Dulbecco's modified Eagle's medium in the presence of $2.5 \mathrm{mM}$ L-glutamine and 5\% foetal bovine serum (FBS). Caco-2 human intestinal colon carcinoma cells were propagated in modified Eagle's medium supplemented with $1.0 \mathrm{mM}$ sodium pyruvate, $0.1 \mathrm{mM}$ non essential amino acids, $1.5 \mathrm{~g} / \mathrm{l}$ sodium pyruvate and 20\% FBS. Madin-Darby canine kidney (MDCK) cells were subcultured in modified Eagle's medium complemented with $2 \mathrm{mM}$ L-glutamine, modified Earle's balanced salt solution (sodium bicarbonate free) and sterile water (to achieve a final concentration of $1.5 \mathrm{~g} / \mathrm{l}$ sodium bicarbonate) next to $0.1 \mathrm{mM}$ non-essential amino acids, $1.0 \mathrm{mM}$ sodium pyruvate and $10 \%$ FBS. SHSY5Y neuroblastoma cells were cultivated in a $1: 1$ (v/v) mixture of Eagle's minimum essential medium and Ham's F12 medium containing 10\% FBS. Vero cells were grown in Medium 199 enriched with 5\% FBS. Growth medium was changed twice a week and cells were passed at confluence using a $0.1 \%$ trypsin solution (Gibco BRL) in Dulbecco's phosphate-buffered $\mathrm{Ca}^{2+}$ - and $\mathrm{Mg}^{2+}$-free saline. Cell numbers were counted in a haemocytometer (Bürker) and cell viability was controlled by the trypan blue exclusion method.

\section{Inhibition of clathrin-mediated endocytosis}

Acidification. Acidification of the cystosol was performed according to a method described by Sandvig et al. (1987).

$\mathrm{K}^{+}$depletion. The procedure for intracellular $\mathrm{K}^{+}$depletion was as described by Larkin et al. (1983).

Drugs. Cells were starved for $30 \mathrm{~min}$ in serum-free medium supplemented with $25 \mathrm{mM}$ Hepes and $1 \% \mathrm{BSA}$, whereafter the incubation was continued at $37^{\circ} \mathrm{C}$ for $60 \mathrm{~min}$ in the same medium in the presence of increasing amounts of chlorpromazine (CPZ), known to interfere with clathrin-mediated en- 
docytosis (Wang et al., 1993), followed by the evaluation of the effects elicited by CT.

Gene silencing. Highly selective blocking of clathrin-mediated endocytosis was accomplished by post-transcriptional gene silencing as described by Vanden Broeck and De Wolf (2006).

Binding of ${ }^{125} \mathrm{I}-\mathrm{CT}$. Treated and control cells, either in monolayer or in suspension, were placed on ice and ${ }^{125} \mathrm{I}-\mathrm{CT}\left(10^{6} \mathrm{cpm} / \mathrm{ml}\right.$; about $\left.1 \mathrm{nM} \mathrm{CT}\right)$ was allowed to bind for at least $30 \mathrm{~min}$ at $4^{\circ} \mathrm{C}$. After washing with ice-cold phosphate-buffered saline (PBS), radioactivity was measured in both growth medium and cells.

Internalization of ${ }^{125} \mathrm{I}$-CT. Internalization of ${ }^{125} \mathrm{I}-\mathrm{CT}$ was always monitored in cell suspensions. After binding of ${ }^{125} \mathrm{I}-\mathrm{CT}$, cells were washed with ice-cold serum-free medium buffered with $25 \mathrm{mM}$ Hepes and subsequently incubated at $37^{\circ} \mathrm{C}$ for the indicated times in prewarmed serum-free medium. With each medium change effector concentrations or experimental conditions were readjusted as required. After incubation cells were washed with PBS. To remove surface-bound ligand, cells were placed for exactly $5 \mathrm{~min}$ at $4^{\circ} \mathrm{C}$ in a solution containing $0.5 \mathrm{M} \mathrm{NaCl}$ and $0.2 \mathrm{M}$ acetic acid $(\mathrm{pH}=2.5)$. Release of surface-bound CT reached an efficiency of about $90 \%$, in accordance with the data of Sorkin and Carpenter (1991). After centrifugation, the cells were washed three times with ice-cold PBS followed by disruption overnight in $0.1 \mathrm{M} \mathrm{NaOH}$. Radioactivity was assayed in both the acid supernatant and lysed cells.

Internalization of ${ }^{125}$ I-transferrin. Internalization of ${ }^{125} \mathrm{I}$-transferrin was monitored in cell suspensions. After binding of ${ }^{125} \mathrm{I}$-transferrin $\left(120 \mathrm{~min}, 4^{\circ} \mathrm{C}\right)$, cells were washed with ice-cold serum-free medium buffered with $25 \mathrm{mM}$ Hepes and subsequently incubated at $37^{\circ} \mathrm{C}$ for the indicated times in prewarmed serum-free medium. With each medium change effector concentrations or experimental conditions were readjusted as required. After incubation, cells were cooled and washed again with PBS. Surfacebound and internalized ${ }^{125} \mathrm{I}$-transferrin were determined as described for $\mathrm{CT}$ in the previous section.

Assay of cyclic AMP. CT-induced activation of adenylate cyclase and intracellular cAMP accumulation were determined as previously described (De Wolf, 2000).

Forskolin-induced activation of adenylate cyclase. In order to exclude direct effects on adenylate cyclase, cells were treated with forskolin, assumed to induce activation of the enzyme without intervening steps. The experiments were performed as described in section 'assay of cAMP' except that the cells were stimulated priorly by a fixed concentration of forskolin $(50 \mu \mathrm{M})$ for $10 \mathrm{~min}$ at $37^{\circ} \mathrm{C}$.
Generation of CT- $\mathrm{A}_{1}$ and analysis by SDS polyacrylamide gel electrophoresis. Generation of CT- $\mathrm{A}_{1}$ was monitored as described previously (De Wolf, 2000).

Measurement of intracellular $\mathrm{pH}$. Measurements of intracellular $\mathrm{pH}$ were performed using the membrane-permeable $\mathrm{pH}$-sensitive probe BCECFAM (2',7'-bis(2-carboxyethyl)-5(6)-carboxyfluorescein acetoxymethyl ester) (Molecular Probes) according to the method described by Rink et al (1980). Calibration was done using the $\mathrm{K}^{+}$-nigericine method (Thomas et al., 1979).

Preparation of clathrin-coated vesicles. Isolation of clathrin-coated vesicles was according to the procedure of Pearse (1982) for isolating this type of vesicles from placenta. Caco- 2 or Caco- $2^{\text {eps- }}$ cells $\left(1.5 \times 10^{8}\right.$ cells $)$ were washed three times with PBS and further incubated at $4^{\circ} \mathrm{C}$ for $2 \mathrm{~h}$ with 0.5 $\mu \mathrm{g} / \mathrm{ml}^{125}$ I-transferrin $\left(1 \mu \mathrm{g} / \mathrm{ml}\right.$, about $\left.2.5 \times 10^{6} \mathrm{cpm}\right)$ or for $1 \mathrm{~h}$ with $0.5 \mu \mathrm{g} / \mathrm{ml}{ }^{125} \mathrm{I}-\mathrm{CT}(1 \mu \mathrm{g} / \mathrm{ml}$, about $1.2 \times 10^{6} \mathrm{cpm}$ ) in binding medium (DMEM containing $20 \mathrm{mM}$ Hepes, ( $\mathrm{pH} 7.4)$ and $0.1 \%(\mathrm{w} / \mathrm{v}) \mathrm{BSA})$. After washing with PBS, cells were warmed up for $2 \mathrm{~min}$ at $31^{\circ} \mathrm{C}$ in binding medium and washed four times in vesicle buffer $(140 \mathrm{mM}$ sucrose, 75 $\mathrm{mM}$ potassium acetate, $10 \mathrm{mM}$ Mes, $\mathrm{pH}$ 6.6, $1 \mathrm{mM}$ EGTA, $0.5 \mathrm{mM}$ magnesium acetate). After draining the dishes, the cells were scraped with a rubber policeman and a protease inhibitor cocktail (Roche) was added. Cells were homogenized on ice in a Potter-Elvehjem homogenizator by passing the suspension 10 times through a 0.2540 inch bore containing a 0.2530 inch diameter ball. Subsequently a post-nuclear supernatant was prepared by centrifugation at $3000 \times g$ for $10 \mathrm{~min}$. To this supernatant self gradient forming Iodixanol (Sigma) was added to obtain a final concentration of $12 \%$ (v/v). Nine milliliters of diluted supernatant were applied to $1.5 \mathrm{ml} \mathrm{15 \%} \mathrm{(v/v)} \mathrm{Iodixanol} \mathrm{in} \mathrm{Sor-}$ vall vertical centrifugation tubes. Centrifugation was continued until equilibrium (Centrikon T2060 (Kontron Instruments) analytical ultracentrifuge; Sorvall TV-850 vertical rotor (Sorvall); $45000 \times g$ for $30 \mathrm{~min}$ at $4^{\circ} \mathrm{C}$ ), whereafter $0.5 \mathrm{ml}$ fractions were collected and further assayed for radioactivity in a Beckman scintillation counter. Optical density of isolated fractions was determined with a Carl Zeiss Jena refractometer.

Western blotting. Fractions were used immediately or stored at $-80^{\circ} \mathrm{C}$. Protein concentrations were determined by the $\mathrm{BCA}^{\circledR}$ method (Pierce Chemicals, Rockford, IL, USA). Fractions were suspended in NuPage LDS Sample Buffer (Invitrogen) before loading on a NuPAGE $12 \%$ bis/Tris polyacrylamide gel (Invitrogen) and processed as described previously (Vanden Broeck \& De Wolf, 2006). 


\section{RESULTS}

Effect of acidification of the cytosol on CT action

Measurement of intracellular $\mathrm{pH}$. To check the effect of the acidity of the incubation medium on the intracellular $\mathrm{pH}, \mathrm{T} 84$ cells were incubated in a series of media covering a $\mathrm{pH}$ range from 5.0 to 7.5. As can be read from the inset in Fig. 2, the outer cellular $\mathrm{pH}$ was paralleled by a similar but less pronounced decrease of the intracellular $\mathrm{pH}$, e.g. an extracellular $\mathrm{pH}=6.0$ (commonly used throughout the experiments) corresponded to the intracellular $\mathrm{pH}=6.4$. This $\mathrm{pH}$ difference can be explained by the cells' capacity to resist cytosolic acidification. At more physiological $\mathrm{pH}$ values, the divergence was less pronounced, with nearly identical inner and outer $\mathrm{pH}$ values.

Under all experimental conditions no difference in viability was found between control and treated cells, even at the lowest $\mathrm{pH}$ tested of 5.0 (not shown).

Binding of cholera toxin. As shown in Table 1, preincubation of Caco-2, T84, SH-SY5Y, MDCK and Vero cells in medium supplemented with HAc $(5 \mathrm{mM})$ to tune the intracellular acidity to $\mathrm{pH}=6.5$ did not alter the ${ }^{125} \mathrm{I}-\mathrm{CT}$ binding capacity appreciably. The binding capacity was measured for cells in suspension as well as in monolayer with a general tendency of a somewhat decreased binding potential of acidified cells in monolayer.

Internalization of cholera toxin. In contrast to the minimal $\mathrm{pH}$ effect on the CT binding, a diminution of CT internalization by about $50 \%$ was observed in all cell types tested when they were treated with $5 \mathrm{mM}$ HAc (Fig. 1A). Surface-bound toxin removal occurred initially rapidly and then decreased, accompanied by a concurrent increase of internalized ${ }^{125} \mathrm{I}-\mathrm{CT}$.

Accumulation of cAMP and adenylate cyclase activation. Incubation of intact cells in acidified medium resulted in a strong suppression of CT-induced cAMP accumulation. All cell lines tested displayed a similar sensitivity to this treatment. As shown in Fig. 1B acidification of the cytosol down to $\mathrm{pH}=6.0$ suppressed the CT action on the level of cAMP accumulation in all cell lines by 60 to $65 \%$.

The impact of acidification was investigated in a $\mathrm{pH}$ range from 5.0 to 7.4. As evidenced from Fig. 2, a maximal inhibitory effect on the ability of CT to raise intracellular CAMP was found below $\mathrm{pH}=6$ for the three cell types tested after $60 \mathrm{~min}$ of incubation. Already from $\mathrm{pH}=7.0$ a significant decrease of CT action amounting to $50 \%$ vs. control was observed. To achieve an optimal balance between the efficient reduction of CT action and cytosolic acidification most experiments were performed in a medium supplemented with $5 \mathrm{mM} \mathrm{HAc}$ adjusted to $\mathrm{pH}=6.0$.

When investigating the time dependence of the inhibitory effect of cytosolic acidification (not shown), it was found that the diminished cAMP accumulation was virtually independent of the moment of acidification, i.e. prior to or upon simultaneous CT administration. All cell types tested showed a similar acidification response.

The inhibitory effect of intracellular acidification appeared to be a partially reversible phenom-
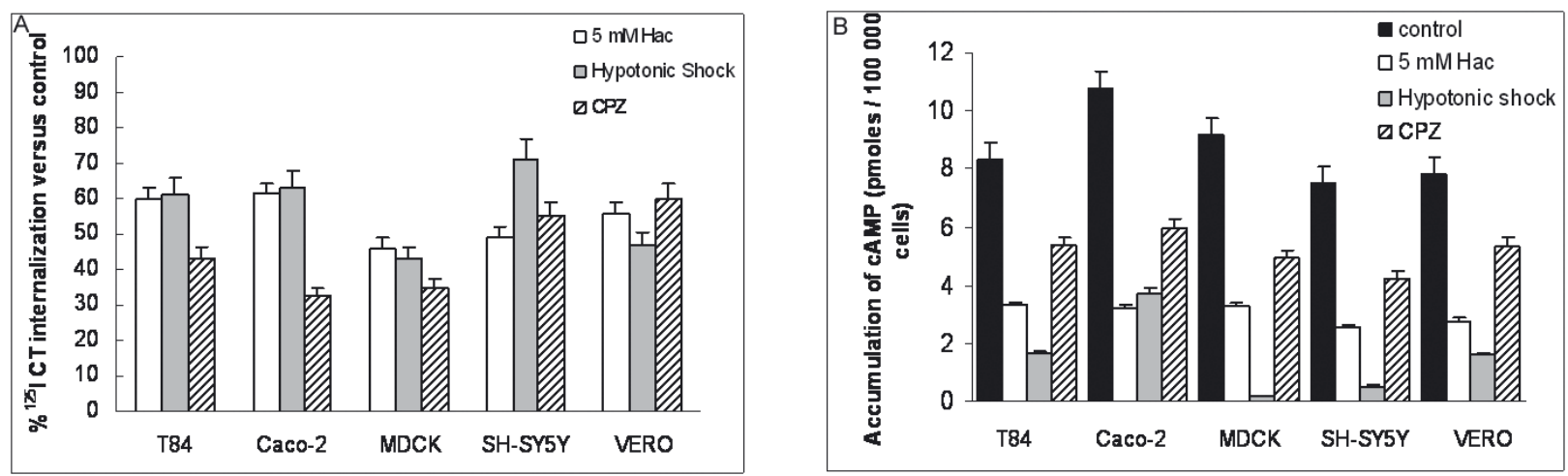

Figure 1. Internalization of ${ }^{125} \mathrm{I}-\mathrm{CT}$ and CT-induced cAMP accumulation in different cell types.

Panel A. Suspensions of cultured cells were preincubated in medium containing $5 \mathrm{mM} \mathrm{HAc}$, adjusted to $\mathrm{pH}$ about 6.0 for $10 \mathrm{~min}$ at room temperature (open bars) or washed with a $\mathrm{K}^{+}$-free isotonic buffer and shocked with a hypotonic $\mathrm{K}^{+}$-free buffer diluted $1: 1$ with $\mathrm{H}_{2} \mathrm{O}$ for $5 \mathrm{~min}$ at room temp. (closed bars) or incubated for $60 \mathrm{~min}$ at $37^{\circ} \mathrm{C}$ with $50 \mu \mathrm{M} \mathrm{CPZ}$ (hatched bars) in control medium prior to binding of ${ }^{125} \mathrm{I}-\mathrm{CT}$. After treatment, ${ }^{125} \mathrm{I}-\mathrm{CT}$ was allowed to bind for 60 min at $4^{\circ} \mathrm{C}$, cells were washed with ice cold PBS and temperature shifted to $37^{\circ} \mathrm{C}$ for $40 \mathrm{~min}$. Cells were further assayed for surface-associated ${ }^{125} \mathrm{I}-\mathrm{CT}$. Panel B. Suspensions of cultured cells were pretreated as described under A. After treatment, cells were placed at $37^{\circ} \mathrm{C}$ for $15 \mathrm{~min}$ after which cholera toxin $(1 \mu \mathrm{g} / \mathrm{ml})$ was added and the cells further incubated for $60 \mathrm{~min}$ at $37^{\circ} \mathrm{C}$. The intracellular concentration of cAMP was measured. Cells under control conditions are depicted by filled bars. Values are means \pm S.D. of triplicate assays from one of at least three similar experiments. 


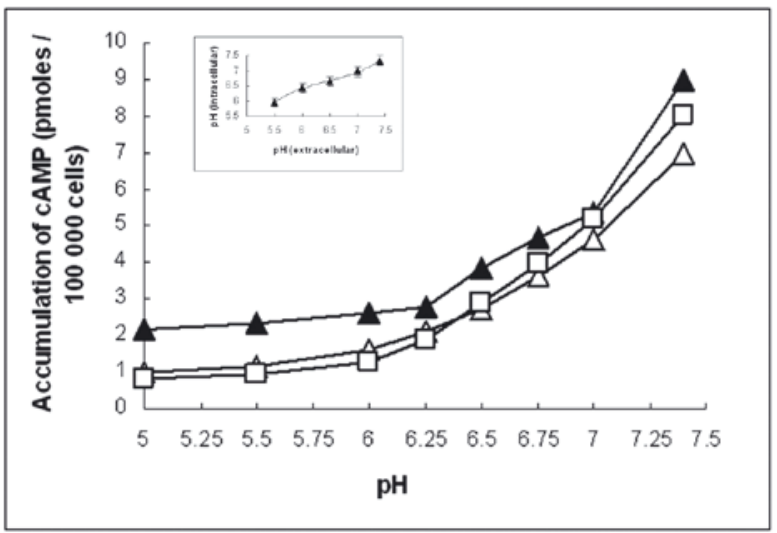

Figure 2. Inhibition of cholera toxin-induced accumulation of cAMP as a function of $\mathrm{pH}$.

Human intestinal T84 cells (closed triangle), SH-SY5Y neuroblastoma cells (open triangles) and Vero cells (open squares) were incubated at $37^{\circ} \mathrm{C}$ for $60 \mathrm{~min}$ with medium at the indicated $\mathrm{pH}$. Subsequently, cholera toxin $(1 \mu \mathrm{g} / \mathrm{ml})$ was allowed to bind at $4^{\circ} \mathrm{C}$, excess $\mathrm{CT}$ washed away and cells were further incubated for $60 \mathrm{~min}$ at $37^{\circ} \mathrm{C}$. The intracellular concentration of cAMP was measured. Values are means of triplicate assays from one of three independent experiments. S.D. values were always below $10 \%$.

enon. Following incubation of the cells for $1 \mathrm{~h}$ at $\mathrm{pH}=6.0$ and substitution of the acidic medium by regular medium before $\mathrm{CT}$ administration, the $\mathrm{CT}$ effect as evaluated by cAMP accumulation was delayed, the lag phase being prolonged by nearly 20 min; also the extent of cAMP production was somewhat reduced (Fig. 3).

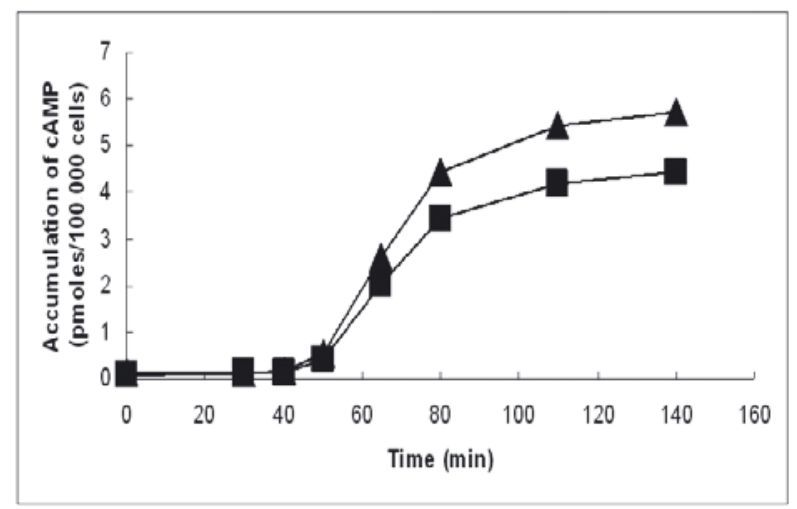

Figure 3. Reversibility of the inhibitory effect of intracellular acidification on $\mathrm{CT}$ action.

Human intestinal T84 (triangles) or Caco-2 cells (squares) in suspension were incubated at $37^{\circ} \mathrm{C}$ for $60 \mathrm{~min}$ in medium with $5 \mathrm{mM}$ HAc $(\mathrm{pH}=6.0)$. After washing with salt solution, cells were resuspended in normal medium at $\mathrm{pH}=7.4$, cholera toxin $(1 \mu \mathrm{g} / \mathrm{ml})$ added and cells incubated for the indicated times, whereafter intracellular cAMP levels were measured. Values are means of triplicate assays from one of three independent experiments. S.D. values were always below $10 \%$.
To exclude any direct effects of acidification on adenylate cyclase activation, intact cells were incubated in the presence of forskolin $(50 \mu \mathrm{M})$, a cell-permeable diterpenoid known to stimulate the adenylate cyclase directly. No significant difference between control and pH-lowered cells was noted (not shown). This observation was confirmed when membranes isolated from control and HAc- treated cells were exposed to in vitro generated CT- $\mathrm{A}_{1}$, the enzymatically active subunit of the holotoxin which finally activates the adenylate cyclase. In both acidified and control cells, no significant difference in the extent of activation was observed (not shown).

Effect of acidification of the cytosol on the generation of active CT- $\mathrm{A}_{1}$. Small amounts of CT$\mathrm{A}_{1}$ appeared in the cytoplasm after a delay of about 15-20 min, increasing in a time-dependent manner and reaching a value of about $4.5 \%$ under control conditions $\left(37^{\circ} \mathrm{C}, 60 \mathrm{~min}\right)$. In acid-treated cells the generation of catalytically active CT- $\mathrm{A}_{1}$ was nearly completely suppressed; after $1 \mathrm{~h}$ incubation only $0.5 \%$ of CT-A was converted into CT- $\mathrm{A}_{1}$ (Fig. 4). The initial amount at time zero of cell-associated CT-A converted to CT- $\mathrm{A}_{1}$ was subtracted as background value and is probably due to non-specific reduction of CT-A despite the presence of NEM.

\section{Effect of $\mathrm{K}^{+}$depletion on $\mathrm{CT}$ action}

Measurement of intracellular $\mathrm{pH}$. Under conditions of $\mathrm{K}^{+}$depletion followed by further incubation with potassium-free medium $(\mathrm{pH}=7.4)$, only a minor decrease of intracellular $\mathrm{pH}$ was found, excluding any side effects of hypotonic shock at the level of intracellular acidity (not shown). Viability of the shocked cells as determined by the trypan blue exclusion method amounted to $98 \pm 0.9 \%$.

Binding of cholera toxin. As observed after intracellular acidification, also after $\mathrm{K}^{+}$depletion and incubation in $\mathrm{K}^{+}$-free medium $\mathrm{CT}$ binding was not altered to any appreciable extent in Caco-2, T84, MDCK, SH-SY5Y and Vero cells (Table 1).

Internalization of cholera toxin. The effect of hypotonic shock followed by $\mathrm{K}^{+}$depletion on $\mathrm{CT}$ internalization was strongly cell-type-dependent (Fig. 1A). In MDCK cells the uptake of CT was reduced down to $40 \%$, while in the other cells a gradual but varying decrease of cell-surface CT was observed in function of incubation time, the CT uptake being the least affected in the SH-SY5Y cell line.

Accumulation of cAMP and adenylate cyclase activation. In contrast to the effect of acidification, the response of the different cell types to $\mathrm{K}^{+}$ depletion was much more diverse with regard to the ability of CT to raise intracellular levels of cAMP (Fig. 1B). In T84 and Vero cells, but even more in 
Table 1. CT binding to various cell types.

Treated and control cells, either in monolayer (ML) or in suspension (S), were placed on ice and ${ }^{125} \mathrm{I}-\mathrm{CT}\left(10^{6} \mathrm{cpm} / \mathrm{ml} ; \sim 1\right.$ $\mathrm{nM} \mathrm{CT}$ ) was allowed to bind for at least $30 \mathrm{~min}$ at $4^{\circ} \mathrm{C}$. After washing cell-bound radioactivity was measured.

\begin{tabular}{lcccccccccc}
\hline & \multicolumn{2}{c}{ Caco-2 } & \multicolumn{2}{c}{ T84 } & \multicolumn{2}{c}{ SH-SY5Y } & \multicolumn{2}{c}{ MDCK } & \multicolumn{2}{c}{ Vero } \\
\hline & ML (\%) & S (\%) & ML (\%) & S (\%) & ML (\%) & S (\%) & ML (\%) & S (\%) & ML (\%) & S (\%) \\
\hline Control & 100.0 & 100.0 & 100.0 & 100.0 & 100.0 & 100.0 & 100.0 & 100.0 & 100.0 & 100.0 \\
Acidification & 93.7 & 94.3 & 86.3 & 103.9 & 78.6 & 95.4 & 87.1 & 83.7 & 86.2 & 106.5 \\
K $^{+}$depletion & 90.3 & 96.3 & 92.9 & 99.3 & 90.5 & 93.0 & 93.3 & 84.7 & 83.7 & 98.8 \\
Chlorpromazine & 95.5 & 94.7 & 88.8 & 92.5 & 93.7 & 95.9 & 96.8 & 81.6 & 79.0 & 113.9 \\
Epsin-deficient & 100.4 & 104.9 & $/$ & $/$ & $/$ & $/$ & $/$ & $/$ & $/$ & $/$ \\
\hline
\end{tabular}

All experiments were performed at least in triplicate with an overall S.D. of less than $7 \%$.

MDCK and SH-SY5Y cells, the inhibitory effect was much more pronounced after $\mathrm{K}^{+}$depletion than after acidification. On the other hand, in Caco-2 cells a nearly similar inhibition was observed upon $\mathrm{K}^{+}$depletion and acidification.

A direct effect of $\mathrm{K}^{+}$depletion on adenylate cyclase activation was excluded based on experiments with forskolin. Also activated CT (CT- $\left.\mathrm{A}_{1}\right)$ induced stimulation of adenylate cyclase after preparing crude membranes displayed no differences between control and potassium-depleted cells under the conditions used (not shown).

\section{Effect of chlorpromazine on CT action}

Binding of cholera toxin. As shown in Table 1, administration of CPZ did not elicit any effect at the level of CT binding in all cells investigated, either in monolayer or in suspension, even at the highest CPZ concentration of $100 \mu \mathrm{M}$ tested.

Internalization of cholera toxin. All experiments were performed at a final concentration of 50 $\mu \mathrm{M}$ CPZ. The response at the level of CT internalization varied between the different cell types. Caco2 and MDCK cells were the most CPZ-sensitive (approx. $65 \%$ reduction), Vero and $\mathrm{SH}-\mathrm{SY} 5 \mathrm{Y}$ cells the most resistant (about $40-45 \%$ reduction) and T84 cells occupied an intermediate position (about 55\% reduction) (Fig. 1A).

Accumulation of cAMP and adenylate cyclase activation. The sensitivity to the drug varied depending on the cell type (Fig. 1B). As shown in Fig. $5 \mathrm{~A}$, to reduce the cAMP accumulation in intestinal T84 cells down to $50 \%$, a concentration of 20 $\mu \mathrm{M} \mathrm{CPZ}$ was needed. To achieve the same reduction in Caco-2 and MDCK cells up to about $60 \mu \mathrm{M} \mathrm{CPZ}$ had to be administered to the cells. SH-SY5Y and Vero cells were more resistant to the drug. In Vero cells, even at $100 \mu \mathrm{M} \mathrm{CPZ}, 50 \%$ reduction of cAMP accumulation could not be attained.

Interestingly, in contrast to the findings after acidification or $\mathrm{K}^{+}$depletion, when verifying the $\mathrm{CPZ}$ effect on forskolin-activated adenylate cyclase, dramatic reductions of the enzymatic activity were registered, the phenomenon being strongly cell-typedependent (Fig. 5B). At $50 \mu \mathrm{M} \mathrm{CPZ} \mathrm{quasi} \mathrm{nihil} \mathrm{or}$ only limited inhibition was observed in T84, MDCK and Vero cells, while in Caco-2 and SH-SY5Y cells an inhibitory effect of over $60 \%$ was found. At $100 \mu \mathrm{M}$ CPZ forskolin-activated adenylate cyclase was suppressed severely in all cell types: by about $60 \%$ of the control in Vero and MDCK cells, over $80 \%$ in T84 cells and over $90 \%$ up in SH-SY5Y and Caco-2 cells.

Activated CT (CT- $\left.\mathrm{A}_{1}\right)$-induced stimulation of adenylate cyclase in crude membranes displayed no

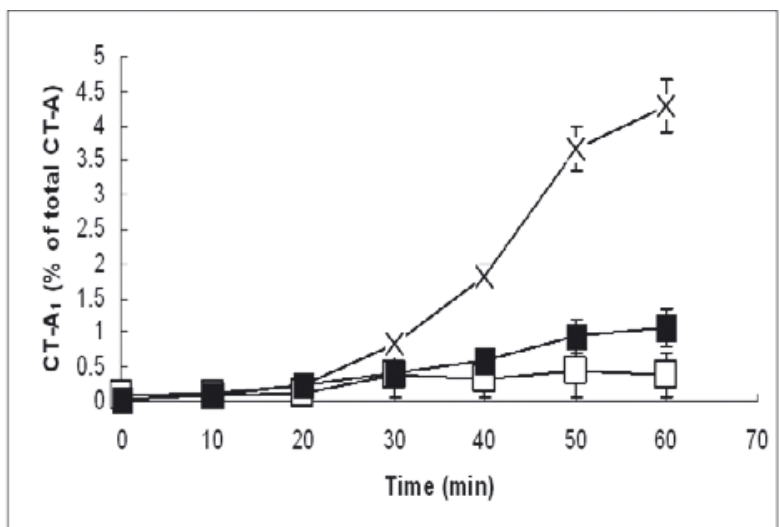

Figure 4. Effect of acidification and epsin-deficiency on the generation of $\mathrm{CT}-\mathrm{A}_{\mathbf{1}}$.

Vero cells were grown in Petri dishes and preincubated for $10 \mathrm{~min}$ at room temp. in medium containing $5 \mathrm{mM}$ HAc $(\mathrm{pH}=6.0)$. After replacement by ice-cold serum-free medium containing ${ }^{125} \mathrm{I}-\mathrm{CT}$ supplemented with $5 \mathrm{mM}$ HAc $(\mathrm{pH}=6.0)$ (open squares), cells were further incubated for the indicated times at $37^{\circ} \mathrm{C}$. Control cells (crosses) were also preincubated for $10 \mathrm{~min}$ at room temp. in normal serum-free medium, whereafter also the $\mathrm{CT}-\mathrm{A}_{1}$ generation was measured following ${ }^{125} \mathrm{I}-\mathrm{CT}$ administration. Caco-2 ${ }^{\text {eps- }}$ cells (closed squares) were grown till confluence and used directly. Cells were scraped and collected by low speed centrifugation. Generation of CT- $\mathrm{A}_{1}$ was determined after separation on SDS/PAGE measuring the amount of radioactivity in the CT- $\mathrm{A}_{1}$ lanes as described in the Materials and Methods section. Values are means \pm S.D. of triplicate assays from one of three independent experiments. 

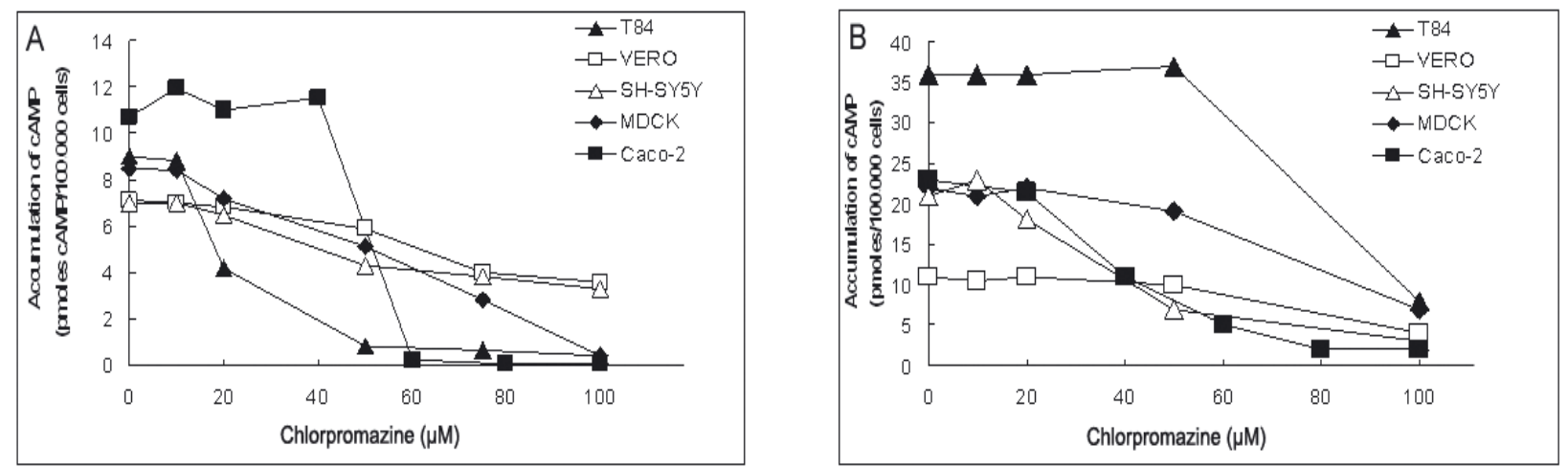

Figure 5. Effect of different concentrations of chlorpromazine on CT- and forskolin-induced cAMP accumulation in different cell types.

Panel A. Suspensions of human intestinal T84 (closed triangles) and Caco-2 (closed squares) cells, SH-SY5Y (open triangles) cells, MDCK (closed diamonds), or Vero (open squares) cells were preincubated for 60 min at $37^{\circ} \mathrm{C}$ with different concentrations of $\mathrm{CPZ}$ as indicated. After treatment, cholera toxin $(1 \mu \mathrm{g} / \mathrm{ml})$ was added, allowed to bind and cells were further incubated for $60 \mathrm{~min}$ at $37^{\circ} \mathrm{C}$, whereafter intracellular levels of cAMP were measured. Panel B. Cells were also stimulated with forskolin for $30 \mathrm{~min}$ at $37^{\circ} \mathrm{C}$ after preincubation with the indicated concentrations of $\mathrm{CPZ}$. Values are means of triplicate assays from one of three independent experiments. S.D. values were always below $10 \%$.

differences under the working conditions between control and CPZ-treated cells (not shown).

Inhibition of clathrin-mediated endocytosis by shRNA targeting epsin

Binding of cholera toxin. The binding of ${ }^{125} \mathrm{I}-$ $\mathrm{CT}$ to Caco-2 ${ }^{\text {eps- }}$ cells in monolayer or suspension was not affected as a result of cell transformation with an shRNA-encoding construct directed against epsin mRNA (Table 1).

Internalization of cholera toxin. In parallel with the decreased transferrin internalization (Fig. 6B) also a reduction of CT uptake amounting to about $60 \%$ was observed in the Caco-2 $2^{\text {eps- }}$ cells as compared to the control Caco-2 cell line (Fig. 6A).

Accumulation of cAMP and adenylate cyclase activation. As depicted in Fig. 7, the decreased CT uptake was paralleled by a nearly equal, also up to about $65 \%$, lowering of the CT-induced cAMP accumulation versus control cells (wild type Caco-2 cells and Caco-2 ${ }^{\text {ss }}$ cells, transfected with a functional, non-targeting scrambled sequence).

Incubation of Caco-2 $2^{\text {eps- }}$ cells with $50 \mu \mathrm{M}$ forskolin showed no significant difference in adenylate cyclase activation compared to control Caco-2 cells, excluding a direct effect of the genetic modification on the activity of adenylate cyclase (not shown).
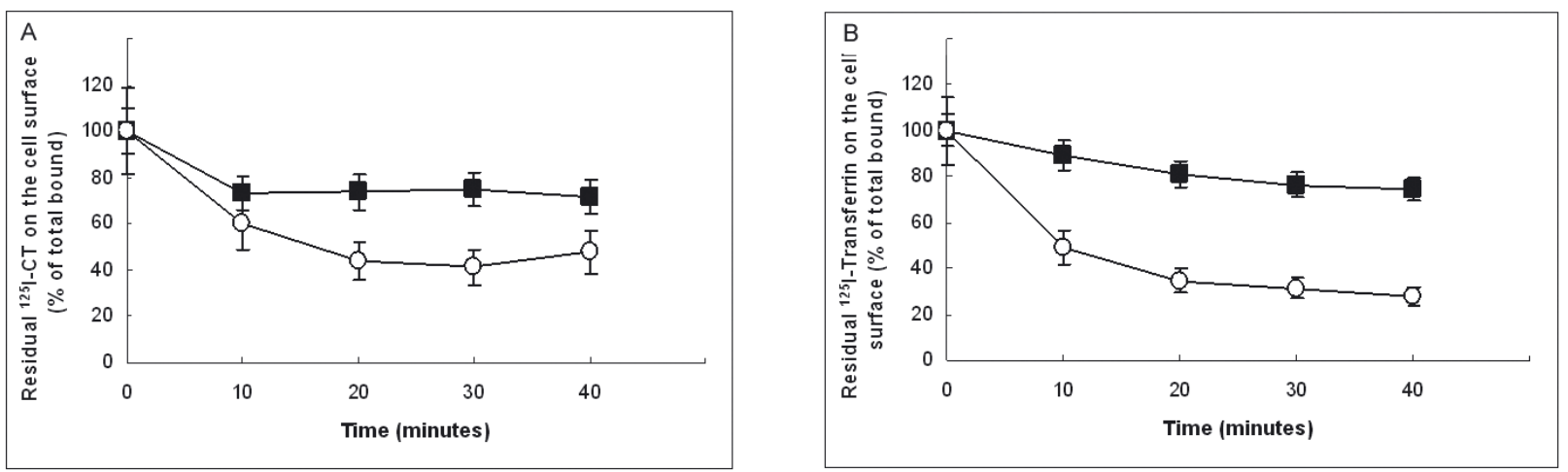

Figure 6. Effect of reduced epsin expression on the internalization of CT.

Panel A. Caco-2 (circles) and Caco-2 ${ }^{\text {eps- }}$ cells (squares) in suspension were cooled on ice and ${ }^{125}$ I-CT was allowed to bind for $60 \mathrm{~min}$. Cells were washed 3 times with ice-cold PBS, further incubated at $37^{\circ} \mathrm{C}$ for the indicated times and temperature shifted to $4^{\circ} \mathrm{C}$ to inhibit endocytosis. Surface-bound ${ }^{125} \mathrm{I}-\mathrm{CT}$ was removed using $0.1 \mathrm{M} \mathrm{HAc}(\mathrm{pH}=2.5)$ and samples were assayed for radioactivity. Panel B. Caco-2 (circles) and Caco- $2^{\text {eps- }}$ cells (squares) in suspension were preincubated for $120 \mathrm{~min}$ on ice in medium containing ${ }^{125}$ I-transferrin and further processed as described. Values are means \pm S.D. of duplicate assays from one of three independent experiments. 


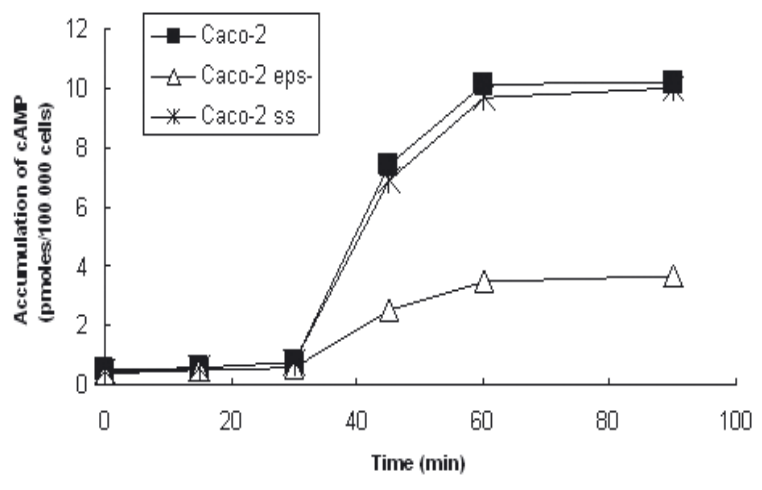

Figure 7. Effect of reduced epsin expression on the ability of cholera toxin to raise the intracellular concentration of cAMP.

Suspensions of cultured wild type Caco-2 cells (closed squares), Caco-2 $2^{\text {ss }}$ (crosses) and Caco- $2^{\text {eps- }}$ (open triangles) were incubated with CT $(1 \mu \mathrm{g} / \mathrm{ml})$ on ice for 30 min, washed with ice-cold PBS and incubated at $37^{\circ} \mathrm{C}$ for the indicated times. The Caco- $2^{\text {ss }}$ cell line, engineered by transfection with a functional, non-targeting scrambled shRNA sequence and wild type Caco-2 cells were used as negative controls. The intracellular concentration of cAMP was monitored. Values are means of triplicate assays from one of three independent experiments. S.D. values were always below $10 \%$.

Effect of reduced epsin expression on the generation of catalytically active CT- $\mathrm{A}_{1}$. In Caco$2^{\text {eps- }}$ cells, the generation of catalytically active CT$\mathrm{A}_{1}$ was strongly suppressed; after $1 \mathrm{~h}$ incubation, only about $1.0 \%$ of CT-A was converted into CT- $\mathrm{A}_{1}$ (Fig. 4).

Effect of epsin depletion on the association of CT with clathrin-coated vesicles. Figure 8 represents the distribution of internalized ${ }^{125} \mathrm{I}-\mathrm{CT}$ (panel A) and ${ }^{125}$ I-transferrin (panel B) over the Iodixanol gradient after incubating Caco-2 and Caco-2 ${ }^{\text {eps- }}$ cells with these ${ }^{125} \mathrm{I}$-labelled ligands. All radioactivity profiles show a peak equilibrating at a density of 1.05, matching the density of clathrin-coated vesicles as reported by Pearse (1982). In addition, these ${ }^{125}$ I-labelled vesicles cosedimented with the clathrin heavy chains in the gradient as illustrated by Western blotting (Fig. 8). From Fig. 8B, a dramatic reduction of transferrin-loaded coated vesicle generation (about $50 \%$ ) becomes obvious. Repeating the experiments with ${ }^{125} \mathrm{I}-\mathrm{CT}$ resulted in similar distribution profiles with again a striking depletion of coated vesicle formation by about $40 \%$ in Caco-2 $2^{\text {eps- }}$ cells (Fig. $8 \mathrm{~A}$ ).

\section{DISCUSSION}

For the functional internalization of CT different entry routes have been proposed. The CT receptor, $\mathrm{GM}_{1}$, being enriched in detergent-insoluble microdomains or lipid rafts, a number of researchers have focussed on the potential role of lipid raft/ caveolae-assisted uptake of CT. These studies were mainly based on the use of pharmaceutical inhibitors assumed to affect selectively DIG's by interfering with the cholesterol content of the plasma membrane. For instance cyclodextrins (Ilangumaran \& Hoessli, 1998) are capable of extracting cholesterol out of the membrane, whereas filipin/nystatin binds and complexes cholesterol (Schnitzer et al., 1994), in this way perturbing normal membrane function. In all those studies, administration of the cholesterolinteracting drugs resulted in a significant reduction of internalization of CT (Ilangumaran \& Hoessli, 1998), leading to the conclusion that CT was internalized via a non-clathrin-mediated route into the cell. However, it should be emphasized that other
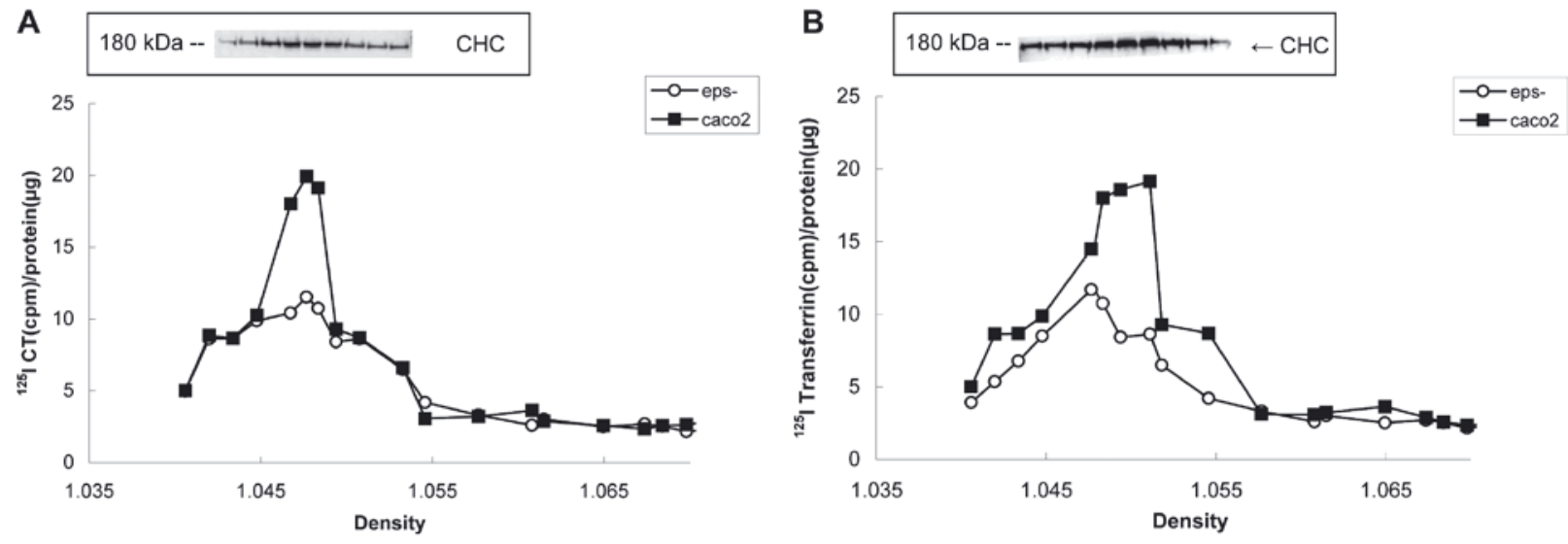

Figure 8. Isolation of clathrin-coated endocytic vesicles and Western blotting.

${ }^{125} \mathrm{I}-\mathrm{CT}$ (A) or ${ }^{125} \mathrm{I}$-transferrin (B) was bound to Caco-2 (closed squares) or Caco-2 ${ }^{\text {eps- }}$ (open circles). Cells were homogenized and a post-nuclear supernatant prepared before OptiPrep density gradient centrifugation. Fractions $(500 \mu l)$ were sampled for radioactivity and assayed for clathrin heavy chain by semi-quantitative Western blotting. The figure displays one representative experiment out of three independent ones. 
groups have reported that cholesterol depletion with cyclodextrins not only disrupts raft structures, but also flattens clathrin lattices and reduces the proportion of deeply invaginated pits (Rodal et al., 1999). Therefore, the drug-induced inhibition of CT internalization could reflect either a disruption of lipid rafts/caveolae and/or a perturbation at the level of clathrin lattices. Accordingly, the data collected in experiments with cholesterol-affecting drugs must be carefully interpreted. Studying functional internalization is even more complicated since intracellular transport of $\mathrm{CT}$ is $\mathrm{M} \beta \mathrm{CD}$-sensitive (Shogomori \& Futerman, 2001).

Another argument against caveolae-mediated endocytosis of CT comes from the time course of the CT-induced cAMP accumulation in several cell types (De Wolf, 2000), implying fast binding, internalization and intracellular transport of $\mathrm{CT}$ from the cell surface towards its intracellular target, the stimulatory $\mathrm{G}$ protein of adenylate cyclase. Indeed, within about $20 \mathrm{~min}$ after $\mathrm{CT}$ intoxication, the toxic effect, i.e. the increase of intracellular cAMP, can be observed. Also internalization of the transferrin receptor, a marker for clathrin-mediated endocytosis, is a fast phenomenon (Moya et al., 1985), whereas caveolae-mediated internalization is described as a slow process (about $3 \mathrm{~h}$ ). Moreover, caveolae appear to be very stable structures of the plasma membrane (Thomsen et al., 2002; Carver \& Schnitzer, 2003).

In this paper, we report on the perturbation of the clathrin-mediated endocytic system in several cell lines using different experimental approaches and evaluate the effects of blocking this entry route on the internalization and toxicity of CT.

Basic biochemical methods like acidification of the cytosol or $\mathrm{K}^{+}$depletion are still commonly applied to study clathrin-mediated internalization processes. Both experimental approaches have been reported to be more selective for the clathrin-mediated internalization route than to the other entry routes (Brech et al., 1998). Although both acidification of the cytosol and $\mathrm{K}^{+}$depletion inhibit the uptake of TfR, their modes of action are different. Acidification of the cytosol inhibits coated pits from pinching off from the cell surface (Sandvig et al., 1987), while $\mathrm{K}^{+}$ depletion prevents the formation of coated pits at the inner cell surface by interfering with the clathrin triskelions/AP-2 adaptor interaction (Larkin et al., 1983). However, it should be stressed that when using these basic biochemical techniques, side effects can never be excluded.

Nevertheless, our data exploiting these techniques demonstrate that, although $\mathrm{CT}$ binding to most cell types was hardly affected, CT uptake was highly reduced and accompanied by a strongly suppressed toxin action, supporting an involvement of coated vesicles in CT internalization. The effects of both treatments were similar in all cell lines tested reflecting the specificity of these two experimental approaches. As no direct inhibition of adenylate cyclase could be excluded, forskolin-induced stimulation of the enzyme was measured in both acidified and $\mathrm{K}^{+}$depleted cells. In either condition, no differences in activation degree were noticed versus the controls. Also with crude membranes isolated from HAc-treated cells, the same activation of adenylate cyclase was found upon exposure to in vitro generated CT- $\mathrm{A}_{1}$. Moreover, the $\mathrm{pH}$ activity curve of adenylate cyclase displays a broad $\mathrm{pH}$ optimum ranging from $\mathrm{pH}=6.5$ to 9.5 (Sanders et al., 1986). As in our experiments the cytosolic $\mathrm{pH}$ was maintained at $\mathrm{pH}=$ about 6.5 , theoretically no direct effects on adenylate cyclase at this lower $\mathrm{pH}$ were to be expected. As a conclusion, neither acidification nor $\mathrm{K}^{+}$depletion elicited any direct effect on adenylate cyclase.

As a third alternative experimental approach to suppress clathrin-assisted uptake, we used the drug CPZ that has been shown to exert specific inhibitory effects on the clathrin-mediated endocytic process (Sofer \& Futerman, 1995). Treatment with CPZ causes clathrin lattices to assemble on endosomal membranes, simultaneously preventing coated pit formation at the plasma membrane (Wang et al., 1993).

Our data reveal that CPZ suppresses the internalization of $\mathrm{CT}$ in all cell types tested, further supporting the involvement of classical coated vesicles in the endocytic process. Interestingly, a prominent cell-dependent sensitivity was noted; e.g., in T84 cells only $20 \mu \mathrm{M} \mathrm{CPZ}$ was required to achieve a $50 \%$ reduction of cAMP accumulation, while Vero cells were much more resistant, needing more than $100 \mu \mathrm{M} \mathrm{CPZ}$ to attain the same degree of reduction. This cell CPZ-sensitivity and accompanying variability for $\mathrm{CT}$ internalization have also been reported by other authors. In hippocampal neurons (Sofer \& Futerman, 1995), $25 \mu \mathrm{M} \mathrm{CPZ}$ was sufficient to block the internalization process of $\mathrm{CT}$ by about $50 \%$, while according to Orlandi and Fishman (1998) relatively high concentrations of CPZ are required for inhibition of CT uptake by Caco-2 cells, in agreement with the results in this study. On the other hand, according to Ma and Lim (2003) much lower CPZ concentrations are sufficient to inhibit significantly the internalization process in the same cell line, although it should be noted that those authors studied the uptake of chitosan and associated insulin instead of CT.

It should be mentioned that $\mathrm{CPZ}$ also generates direct effects on the intracellular $\mathrm{CT}$ target, i.e. adenylate cyclase, as indicated by the inhibition of forskolin-stimulated adenylate cyclase. This direct effect of CPZ on adenylate cyclase therefore complicates the quantitative assessment of the func- 
tional internalization based on changes of cAMP accumulation.

As a final experimental approach, a Caco$2^{\text {eps- }}$ cell line was developed, constitutively expressing shRNA targeting the mRNA coding for epsin (Vanden Broeck \& De Wolf, 2006). Epsin is an intrinsic regulatory component of clathrin-mediated endocytosis and to our knowledge the EPN1 gene has been proven to be highly specific for this type of internalization process. The protein is involved in the induction of membrane curvature, clathrin polymerization and recruitment of the AP-2 complex (Ford et al., 2002). The cell line is characterized by a severe depletion of epsin expression, resulting in a dramatic reduction of clathrin-mediated endocytosis as evidenced from the attenuated transferrin internalization. We have shown that in this Caco-2 ${ }^{\text {eps- }}$ cell line, the CT uptake was also severely suppressed, paralleled by a nearly equal lowering of the ability of CT to raise cytosolic cAMP levels.

Summarizing, all our data point to an involvement of clathrin-coated pits in the functional uptake of CT. On the other hand, one cannot negate the experimental evidence obtained with cholesterol-interacting drugs by others (Orlandi \& Fishman, 1998) and also in our laboratory (unpublished), suggesting CT uptake via non-clathrin-mediated endocytic mechanisms. These divergent opinions might be reconciled by the hypothesis that there is not always a strict segregation of clathrin-dependent and raft-dependent endocytic pathways and that CT uptake could rely on a crosstalk between signalling and internalization components. In other words, the site of CT binding does not necessarily coincide with the site of internalization. Such a model has already been proposed by Shogomori and Futerman (2001) for uptake of CT by hippocampal neurons, assuming initial binding of the toxin occurring in a $\mathrm{GM}_{1}$ hotspot (lipid raft) followed by internalization via a clathrin-dependent mechanism. This CT/raft complex could either diffuse directly into the coated pit and be internalized, as the dimensions of a standard coated pit (70 nm to $100 \mathrm{~nm}$ ) (Ehrlich et al., 2004) are sufficient to accept an intact lipid raft. Nevertheless, it has been described that coated pits are depleted in raft components (Nichols, 2003). Alternatively, the CT/GM1 complexes might move laterally from the raft, subsequently being internalized via the clathrinmediated pathway.

In conclusion, all our data resulting from experiments applying different approaches to affect clathrin-assisted endocytosis confirm that functional internalization of CT occurs, at least partially, via the clathrin-mediated uptake system. The most convincing data were gathered from the development of a Caco-2 ${ }^{\text {eps- }}$ cell line by RNA interference which was severely depleted in epsin, a regulatory protein as- sumed to be exclusively associated with the clathrin-mediated endocytosis at the level of the plasma membrane. The lowered epsin levels in this cell line resulted in a firm decrease in TfR uptake, as well as of CT. The latter effect was paralleled by a drastic reduction of the physiological effects generated intracellularly as a consequence of $\mathrm{CT}$ intoxication.

\section{Acknowledgements}

The authors are indebted to Rony Goossens and Karen Verstraeten for skilful technical assistance. They are also grateful to Lieve Naessens for care in typing and editing of the manuscript. One of the coauthors, A.R.L., worked for many years on the topic of isoprenoid biochemistry but left the field several years ago. He highly appreciates that this paper has been accepted for publication in this issue in honour of Professor dr. T. Chojnacki. A.R.L. admires T.C. as an outstanding scientist, but also has experienced him as a most friendly and gentle person. A.R.L. will always cherish the memory of their acquaintance and the good moments they have shared.

This work was financially supported by RAFO grant RAFO/1 DEWOM KP02.

\section{REFERENCES}

Brech A, Kjeken R, Synnes M, Berg T, Roos N, Prydz K (1998) Endocytosed ricin and asialoorosomucoid follow different intracellular pathways in hepatocytes. Biochim Biophys Acta 1373: 195-208.

Carver LA, Schnitzer JE (2003) Caveolae: mining little caves for new cancer targets. Nat Rev Cancer 3: 571-581.

Damke H, Baba T, Warnock DE, Schmid SL (1994) Induction of mutant dynamin specifically blocks endocytic coated vesicle formation. J Cell Biol 127: 915-934.

de Haan L, Hirst R (2004) Cholera toxin: a paradigm for multi-functional engagement of cellular mechanisms. Mol Membr Biol 21: 77-92.

De Wolf MJS (2000) A dipeptide metalloendoprotease substrate completely blocks the response of cells in culture to cholera toxin. J Biol Chem 275: 30240-30247.

Ehrlich M, Boll W, Van Oijen A, Hariharan R, Chandran K, Nibert ML, Kirchhausen T (2004) Endocytosis by random initiation and stabilization of clathrin-coated pits. Cell 118: 591-605.

Fishman PH, Orlandi PA (2003) Cholera toxin internalization and intoxication. J Cell Sci 116: 431-432.

Ford MG, Mills IG, Peter BJ, Vallis Y, Praefcke GJ, Evans PR, McMahon HT (2002) Curvature of clathrin-coated pits driven by epsin. Nature 419: 361-366.

Fra AM, Williamson E, Simons K, Parton RG (1994) Detergent-insoluble glycolipid microdomains in lymphocytes in the absence of caveolae. J Biol Chem 269: 30745-30748.

Fraker PJ, Speck JC Jr (1978) Protein and cell membrane iodinations with a sparingly soluble chloroamide, 1,3,4,6tetrachloro-3a,6a-diphenylglycoluril. Biochem Biophys Res Commun 80: 849-857. 
Harder T, Simons K (1997) Caveolae, DIGs, and the dynamics of sphingolipid-cholesterol microdomains. Curr Opin Cell Biol 9: 534-542.

Ilangumaran S, Hoessli DC (1998) Effect of cholesterol depletion by cyclodextrin on the sphingolipid microdomains of the plasma membrane. Biochem J 335: 433440.

Jobling MG, Holmes RK (2000) Identification of motifs in cholera toxin A1 polypeptide that are required for its interaction with human ADP-ribosylation factor 6 in a bacterial two-hybrid system. Proc Natl Acad Sci USA 97: 14662-14667.

Larkin JM, Brown MS, Goldstein JL, Anderson RG (1983) Depletion of intracellular potassium arrests coated pit formation and receptor-mediated endocytosis in fibroblasts. Cell 33: 273-285.

Ma Z, Lim LY (2003) Uptake of chitosan and associated insulin in Caco-2 cell monolayers: a comparison between chitosan molecules and chitosan nanoparticles. Pharm Res 20: 1812-1819.

Massol RH, Larsen JE, Fujinaga Y, Lencer WI, Kirchhausen $\mathrm{T}$ (2004) Cholera toxin toxicity does not require functional Arf6- and dynamin-dependent endocytic pathways. Mol Biol Cell 15: 3631-3641.

Moya M, Dautry-Varsat A, Goud B, Louvard D, Boquet P (1985) Inhibition of coated pit formation in Hep2 cells blocks the cytotoxicity of diphtheria toxin but not that of ricin toxin. J Cell Biol 101: 548-559.

Nichols BJ (2003) GM1-containing lipid rafts are depleted within clathrin-coated pits. Curr Biol 13: 686-690.

Orlandi PA, Fishman PH (1998) Filipin-dependent inhibition of cholera toxin: evidence for toxin internalization and activation through caveolae-like domains. J Cell Biol 141: 905-915.

Parton RG (1996) Caveolae and caveolins. Curr Opin Cell Biol 8: 542-548.

Pearse B (1982) Coated vesicles from human placenta carry ferritin, transferrin, and immunoglobulin G. Proc Natl Acad Sci 79: 451-455.

Rink TJ, Montecucco C, Hesketh TR, Tsien RY (1980) Lymphocyte membrane potential assessed with fluorescent probes. Biochim Biophys Acta 595: 15-30.

Rodal SK, Scretting G, Garret O, Vilhardt F, van Deurs B, Sandvig K (1999) Extraction of cholesterol with methylbeta-cyclodextrin perturbs formation of clathrin-coated endocytic vesicles. Mol Biol Cell 10: 961-974.

Sanders RB, Bekairi AM, Abulaban FS, Yochim JM (1986) Uterine adenylate cyclase in the rat: responses to a decidual-inducing stimulus. Biol Reprod 35: 100-105.

Sandvig K, Olsnes S, Petersen OW, van Deurs B (1987) Acidification of the cytosol inhibits endocytosis from coated pits. J Cell Biol 105: 679-689.
Schnitzer JE, Oh P, Pinney E, Allard J (1994) Filipin-sensitive caveolae-mediated transport in endothelium: reduced transcytosis, scavenger endocytosis, and capillary permeability of select macromolecules. I Cell Biol 127: 1217-1232.

Shogomori H, Futerman AH (2001) Cholera toxin is found in detergent-insoluble rafts/domains at the cell surface of hippocampal neurons but is internalised via raft-independent mechanism. J Biol Chem 276: 9182-9188.

Sofer A, Futerman AH (1995) Cationic amphiphilic drugs inhibit the internalization of cholera toxin to the Golgi apparatus and the subsequent elevation of cyclic AMP. J Biol Chem 270: 12117-12122.

Sorkin A, Carpenter G (1991) Dimerization of internalised epidermal growth factor receptors. J Biol Chem 266: 23453-23460.

Thomas JA, Buchsbaum RN, Zinniak A, Racker E (1979) Intracellular $\mathrm{pH}$ measurements in Ehrlich ascites tumor cells utilizing spectroscopic probes generated in situ. Biochemistry 18: 2010-2018.

Thomsen P, Roepstorff K, Stahlhut M, van Deurs B (2002) Caveolae are highly immobile plasma membrane microdomains, which are not involved in constitutive endocytic trafficking. Mol Biol Cell 13: 238-250.

Torgersen ML, Skretting G, van Deurs B, Sandvig K (2001) Internalization of cholera toxin by different endocytic mechanisms. J Cell Sci 114: 3737-3747.

Tran D, Carpentier JL, Sawano F, Gorden P, Orsi L (1987) Ligands internalised through coated or noncoated invaginations follow a common intracellular pathway. Proc Natl Acad Sci 84: 7957-7961.

Vanden Broeck D, De Wolf MJS (2006) Selective blocking of clathrin-mediated endocytosis by RNA interference: epsin as target protein. Biotechniques 41: 475-484.

Vanden Broeck D, De Wolf MJS (2007) Vibrio cholerae: cholera toxin. Int J Biochem Cell Biol 39: 1771-1775.

Van Heyningen WE, Carpenter CC, Pierce NF, Greenough WB (1971) Deactivation of cholera toxin by ganglioside. J Infect Dis 124: 415-418.

Wang LH, Rothberg KG, Anderson RG (1993) Mis-assembly of clathrin lattices on endosomes reveals a regulatory switch for coated pit formation. J Cell Biol 123: $1107-1117$

WHO (2006) Cholera 2005. wkly Epidemiol Rec 81: 297-308.

Wolf AA, Fujinaga Y, Lencer WI (2002) Uncoupling of the cholera toxin GM1 ganglioside-receptor complex from endocytosis, retrograde Golgi trafficking, and downstream signal transduction by depletion of membrane cholesterol. J Biol Chem 277: 16249-16256. 